\title{
Diminishing demandingness of parents; children with recurrent infections
}

\author{
Ellen van der $\mathrm{Gaag}^{1^{*}}$, Miriam Münow ${ }^{2}$ \\ ${ }^{1}$ Department of Pediatrics, Hospital Group Twente, Hengelo, The Netherlands; *Corresponding Author: e.gaagvander@zgt.nl \\ ${ }^{2}$ Department of Pediatrics, Marien-Hospital GmbH, Wesel, Germany
}

Received 11 April 2012; revised 9 May 2012; accepted 31 May 2012

\begin{abstract}
Background and Method: Parenting and parenting styles are in favor of authoritative parents compared with non-authoritative parents. These parents display higher levels of both responsiveness and demandingness. We studied the aspect of demandingness using a questionnaire aimed at children aged between 1 and 4 years. 82 Children with recurrent respiratory infections (RRI) and 399 control children were included. Results: Parents of RRI children regulated the quantitative dietary intake of their child less; likewise they gave less stimulation to their children to eat. They also taught their children less on what they can or cannot touch and they argued more with their children (all $p<0.05$ ). However, when it comes to simple rules like watching television or not, the parents of RRI children were very clear. There were however no differences in rules about television watching, computer time or bedtimes. Conclusions: Our study shows that parents of children with RRI are less demanding in complex pedagogic situations that ask for creativity from the parents. However, they are demanding with respect to simple rules. We found no child factors that could explain why children give their parents a hard time. We hypothesize that the parents of RRI children could be less capable of handling complex pedagogic situations (even more complicated by the infections) instead of being unwilling.
\end{abstract}

Keywords: Recurrent Infections; Demandingness; Parenting

\section{INTRODUCTION}

Children with recurrent respiratory infections (RRI) are an internationally common phenomenon. Most of the time, the condition can be addressed as a normal stage in childhood [1]. Children with a high frequency of these infections are nevertheless puzzling, since a medical explanation for the symptoms cannot always be found [2]. In our previous study about children with recurrent respiratory infections without medical explanation, we found that their parents were more concerned about the children. The concern was caused by a fear for serious disease, visiting the doctor more often and administering them more over the counter medication [3]. A possible relation was suggested between the parental insecure attitude and the activated immune system in their children by psychoneuroimmunology. When a parental attitude potentially affects the immune system of the child, the question remains as to what else could also contribute to such a phenomenon? Another possible factor could be parenting itself, the way children are raised and how the children experience their boundaries. There are several parenting styles and thus several ways to become an adult.

Parenting styles influence developmental outcomes for children and adolescents [4,5]. Four parenting style categories were developed based on the parenting dimensions of responsiveness and demandingness, as laid out by Maccoby and Martin [6]. Authoritative parents display high levels of both responsiveness and demandingness. They are warm and sensitive to their child's needs and consistently consider the child's age and maturity when they deal with the child's behavior. Authoritarian parents show low responsiveness and high demandingness. As a result they are often cold, non-supportive, and demanding in their control. Indulgent parents are highly responsive to their children but have low demandingness. They believe that fewer rules and expectations of appropriate behavior benefit children's development. The fourth type, the uninvolved parents, show low levels of both responsiveness and demandingness. In contrast to indulgent parents, they are more focused on themselves instead of being moved by child-centered motivations. The parents have few expectations and rules for their children. They are usually withdrawn and are not involved with 
their children. The reasons behind uninvolved parenting tend to be related to parental psychopathology or other problems.

The effects of parenting style are in favor of authoritative parents compared with non-authoritative parents $[4,5,7]$. Children and adolescents raised by authoritative parents show better developmental outcomes such as greater self-esteem, self-control, moral development, social maturity, and school performance [8]. There is also evidence of a greater psychological well-being, less depression, and less use of substance. These effects can last across a lifespan $[9,10]$.

The two dimensions on which parenting styles are based are responsiveness/warmth and demandingness/ control. These dimensions can be tested by the use of questionnaires $[10,11]$. These questionnaires should however be given retrospectively when the children reach an age at which this is possible. As far as we know there are no questionnaires about parenting style or demandingness which can be used when the children are below 4 years of age. In order to examine the demandingness dimension, we tried to fill this gap by asking the parents the questions instead of the children.

We studied a group of children with a high frequency of recurrent respiratory infections (RRI). These children were without abnormalities found during physical or laboratory examination. We asked the parents of these children (with RRI and health controls) about demandingness. We hypothesized that the demandingness of the parents is decreased if the children have RRI. We also tried to explore delicate distinctions in parental demandingness.

\section{METHODS}

\subsection{Population}

We used a questionnaire to interview the parents of children with RRI and the parents of healthy children. Children with RRI were defined as those aged between 1 and 4 years and who suffer 10 or more days a month from a respiratory infection for the last 3 months. Healthy toddlers were defined healthy if they had respiratory infections for less than 10 days a month. The survey was conducted in the summer and at the beginning of the fall season from April to October 2008. The children with RRI came from the outpatient clinic of the Department of Pediatrics and Otorhinolaryngology, Ziekenhuis Groep Twente, location Hengelo, The Netherlands. The incidence of infections were objectified by the pediatrician or otorhinolaryngologist. The healthy toddlers were recruited at infant welfare clinics in Hengelo, Borne, Delden, Denekamp, Goor, Losser, Markelo, and Oldenzaal, all in The Netherlands.

\subsection{General Information}

We asked parents about gender and age. We inquired with the use of a questionnaire (Appendix), about health, child factors, rules and demandingness.

\subsection{Demandingness and Rules}

We divided the rules related to demandingness into two groups: simple and complex. Simple rules were defined as rules with two options. For example, the child can watch television or not. When he or she watches television, is it 10 minutes or 30 minutes? Parents can opt to have their children taste everything or not. Complex rules were defined as more complex situations, with more than one option depending on the situation. For example, whether parents motivate their child to eat is dependent on the food, the amount of food the child ate that day, if the child was ill, or if they like the food very much. Asking if the child knows what to touch and what not to touch is a pedagogic challenge. It asks for a consistent approach from parents with few exceptions inasmuch as the child is inclined to exploit these situations.

\subsection{Statistics}

For statistical analysis, SPSS for Windows was used (version 13.0 SPSS Inc., United States of America). The chi-square test was used for categorical variables (gender, health of parents, day care attendance). Continuous variables without normal variation were analyzed with the Mann-Whitney test (amount of infection and use of antibiotics, frequency of common cold). When there was normal variation, the student T-test was used (age, time of television watching). To compare the spread of age in all categories for the ordinal variables, the Kruskal-Wallis test was used. For other variables, regression analysis was performed (amount of infection, days of common cold, hours of sleep) to search for significant disturbing factors such as age differences and to correct for these factors.

\section{RESULTS}

\subsection{Descriptives}

In total, 505 questionnaires were filled out. Twentyfour were excluded because the parents noted their own date of birth instead of their child's or because their child was less than 1 year old. Three hundred and ninety-nine questionnaires were returned by the parents of control children. There were 82 from the parents of children with RRI.

Table 1 describes the group characteristics. Gender, day care attendance, and known illnesses were the same 
Table 1. Group characteristics.

\begin{tabular}{lccc}
\hline & RRI Children $n=82$ & Control Children $n=399$ & $p$ Value \\
\hline Female & $45 \%$ & $53 \%$ & 0.25 \\
Age (in years) & 2.3 & 2.8 & $<0.01$ \\
Infections (in 3 months) & 2.29 & 0.45 & $<0.01$ \\
Antibiotic courses (in 3 months) & 0.61 & 0.09 & $<0.01$ \\
Never common cold & $1(1 \%)$ & $68(17 \%)$ & $<0.01$ \\
Chronic common cold & $38(46 \%)$ & $0(0 \%)$ & $<0.01$ \\
Medications used & $24(29 \%)$ & $49(12 \%)$ & $<0.01$ \\
Known illness & $25(31 \%)$ & $48(12 \%)$ & 0.31 \\
Day care center & $72(94 \%)$ & $372(93 \%)$ & 0.93 \\
Parents with chronic illness & $7(9 \%)$ & $11(3 \%)$ & $<0.05$ \\
\hline
\end{tabular}

in both groups. The known illnesses were skin disorders, pulmonary diseases, constipation, and ENT problems. The children with RRI were 6 months younger than those in the control group. All following characteristics were corrected for this confounder (age factor). The children with RRI were selected for their symptoms of common cold and recurrent periods of fever. Therefore, the number of days of common cold, infections, and antibiotic use is increased in the RRI group compared with the control group. They also used more medication, e.g. laxantia or aerosols.

\subsection{Demandingness}

The parents of children with RRI were less demanding of their children as clearly shown in their implementation of the complex rules (Table 2). These situations are complex and involve for example, guidance given at mealtime or the teaching of the rules. The parents of children with RRI regulated less with respect to the quantitative dietary intake of their child. Likewise, they gave less stimulation to their children to eat. They did not dislike the action of stimulating their child (48\% vs $52 \%$ in control children, $\mathrm{p}=0.127$ ), but they did not do it. The parents of children with RRI taught their children less on what they can or cannot touch. They also argued more with their children. If they are in control, there should not be any need to argue. However, when it comes to simple rules like watching television or not, the parents of children with RRI were very clear towards their children (Table 2) and no differences compared with the control children were seen. They were in control of the situation. In the group of children with RRI, no child had influence on watching television compared with $11(2.8 \%)$ in the control group ( $p=0.05)$. We also saw no difference between the two groups in bedtimes
(19.23 $\mathrm{h} \pm 0.42$ or $19.32 \mathrm{~h} \pm 0.40, \mathrm{p}=0.054)$, days a week with fixed bedtimes $(6.27 \pm 0.93$ and $6.39 \pm 0.83$, p $=0.274$ ), or parents allowing delaying tactics when the child goes to bed ( $n=3[3.6 \%)$ or $n=8[2.0 \%), p=$ 0.067).

We saw the same tendency with pastimes. When the children were playing without their parents, we saw no differences between children with RRI and control children. Both groups performed handiworks, played outside, or read books. When they had activities with their parents, we saw the differences. When children with RRI engaged in goal-oriented activities like doing the grocery, watching television, playing soccer, cycling, or helping around the house, there were no differences from the control children. When there were activities that demand greater creativity like doing handiwork together $(n=26$ [32\%) or $n=203$ $[51 \%) \mathrm{p}=0.012)$ or playing a game together $(\mathrm{n}=42$ $[52 \%)$ or $n=272[68 \%) \mathrm{p}=0.046)$, the parents of children with RRI executed it less often.

\subsection{Child Factors}

Because the children were aged between 1 and 4, little evidence is available about a reliable test of behavioral disorders at this age. In our study group no child was diagnosed with a DSM-IV diagnosis like ASS or ADHD. We therefore evaluated the presence of aspects of difficult behavior from the children. The children with RRI tended to be less adventurous and active. They did attract the attention of the parents more often than control toddlers (Table 3). Nevertheless, the children were not more boisterous, violent or slower eaters compared with the control group.

\section{DISCUSSION}

From our study, we got the impression that the parents 
Table 2. Demandingness and rules.

\begin{tabular}{lccc}
\hline & RRI Children $n=82$ & Control Children $n=399$ & $p$ Value \\
\hline Complex rules & & & \\
Parents stimulate child to eat & $35(44 \%)$ & $236(60 \%)$ & $<0.05$ \\
Child decides size of meal & $23(28 \%)$ & $61(15 \%)$ & $369(94 \%)$ \\
Child knows what he/she can touch & $61(80 \%)$ & $29(7 \%)$ & $<0.05$ \\
Parents argue with child & $12(16 \%)$ & & $<0.05$ \\
Simple rules & & $19(5 \%)$ & $<0.01$ \\
Child not allowed to watch television & $15(18 \%)$ & 0.98 & 0.7 \\
Television time (hours a day) & 0.92 & 0.03 & 0.67 \\
Computer time (hours a day) & 0.03 & $348(88 \%)$ & 0.62 \\
Child has to taste everything & $68(86 \%)$ & & \\
\hline
\end{tabular}

Table 3. Child factors of difficult behavior without DSM IV classification.

\begin{tabular}{lccc}
\hline & RRI Children $n=82$ & Control Children $n=399$ & $p$ Value \\
\hline Child is picky eater & $32(40 \%)$ & $132(33 \%)$ & 0.21 \\
Child moves constantly during meals & $33(41 \%)$ & $158(40 \%)$ & 0.27 \\
Child is slow eater & $30(37 \%)$ & $187(47 \%)$ & $<0.05$ \\
Child plays boisterously or violently & $14(18 \%)$ & $46(12 \%)$ & 0.1 \\
Child is adventurous and active & $71(92 \%)$ & $389(98 \%)$ & $<0.05$ \\
Child catches parent's attention & $22(29 \%)$ & $67(17 \%)$ & $<0.05$ \\
\hline
\end{tabular}

of children with RRI are less demanding of their children than control parents are in the absence of any child factor. Strikingly enough, they are demanding when it comes to simple rules, but they are not so with complex rules and situations. Therefore, it is not that they do not apply too few rules or let their children play in total freedom. They do operate rules like allowing their children to watch television or not and determining the amount of time to be spent in front of the television. But when situations become more complex, such as rules that apply to eating habits or teaching the child rules that apply to what they can or cannot touch (unpredictable situations), they abandon the demandingness dimension more readily compared with the control parents. The parents of the control children take a more leading position under complex pedagogic situations.

Possible consequences are described in a study done by Hoerr [11]. In this study, parenting styles are related to food intake. Parents with authoritative or authoritarian styles (high levels of demandingness) could stimulate their children more to eat difficult food types like vegetables compared with indulgent or uninvolved parents (low levels of demandingness). Overweight in children is also related to permissive parenting styles, characterized by few demands but high parental responsiveness [1214]. Besides the food intake and weight gain, several outcomes were found on the psychological well-being of the children [8]. A greater self-esteem is reported on children when parents are highly demanding (and highly responsive) [15]. Parental demandingness helps to form self-control and authentication in children. The guidelines parents set for their children can give them a hold of group and societal standards [16]. Experiences with rules and the consequences of breaking them helps children to form their decision making skills and gain control of their own behavior [17]. Without adequate parental control, children experience multiple difficulties because the outside world consists of all kinds of behavioral rules and standards of manners [18].

The reason for being uninvolved or indulgent (less demanding parenting styles) is not described in other studies. We assume no parent chooses consciously to become uninvolved; psychopathology is obviously not a voluntary choice. For indulgent parents, it can be a belief or conviction that maintaining few rules gives their child all the space that they need to develop himself or herself.

With the results of our study, we hypothesize parents become less demanding when the circumstances become 
more complex. Our results show diminishing demandingness in complex pedagogic situations. When a child has recurrent respiratory infections, this can be construed as an extra difficulty being added, creating more complex situations. Can the parents be less demanding because of the infections? Normally stimulating your child to eat becomes different when he or she is ill. Everybody knows that eating is difficult when you are ill. It doesn't taste the same, the food goes down badly, you want to sleep instead of eat. When the child is ill or beyond the illness period, he or she shall not cooperate and parents have to resort to a lot of creativity to make them eat. Contrastingly, simple rules (with only two options) hardly turn into complex situations. When the child is ill, he or she still goes to bed with the same rituals or he or she still has to taste a new type of food. One gets the impression that the parents are not unwilling but are rather incapable because of the circumstances.

Limitations are clearly present with our study. The simple rules are easy to investigate since it asks the parents to state their opinions and beliefs. The complex rules are more difficult to investigate with single item questions since there are many factors the parents consider during execution. When asked about it, they draw a conclusion on how they usually manage these situations. To make it more standardized and easy for the parents, we formulated multiple choice answers to these questions. Not every aspect of the complex situation could be incorporated in the questionnaire. Future studies can possibly further elucidate this phenomenon.

Secondly, children with RRI are younger than the control children. Some of the differences between the children with RRI and the control children could possibly be explained by this age difference. They are at the beginning of the "terrible two" stage. They tend to be less adventurous, explore less, and attract their parents' attention a lot more. They eat more quickly compared with their elder control counterparts and this could be the reason that their parents have to stimulate them less. The other complex rules cannot be explained by the age difference. It is not common to argue with a two-year-old. Children usually do not decide how much they eat since they decide based on their willingness and not on the belief of what is good for them. Learning what they can and cannot touch starts when the child starts to walk, usually before the age of two. The age of the children could play a role in managing the situations differently but it cannot explain all the differences.

Thirdly, racial or ethnic differences were not taken into account. In future studies all the above mentioned limitations should be investigated further. Therefore, our results should be interpreted with caution until these aspects are studied in a broad context.

\section{CONCLUSION}

Our study shows a trend that parents of children with RRI are less demanding in complex pedagogic situations that ask for more creativity from the parents. However, the parents are demanding with respect to simple rules. We found no child factors that could explain why children give their parents a hard time. The behavior of the children with RRI is the same as the behavior of the healthy control children. We assume that the parents of children with RRI could be less capable of handling complex pedagogic situations instead of being unwilling because of the greater complexity of children with RRI. They do execute rules for their children and they also do not dislike doing that. The more complex it is, the less control the parents of children with RRI seem to impose. Future studies should investigate this complicated area in a broad context before definite conclusions can be made.

\section{ACKNOWLEDGEMENTS}

We thank Professor J. van der Palen (Medical School Twente, University Twente, Enschede, The Netherlands) for assisting us with the statistical analysis.

\section{REFERENCES}

[1] Slatter, M.A. and Gennery A.R. (2008) Clinical immunology review series: An approach to the patient with recurrent infections in childhood. Clinical \& Experimental Immunology, 152, 389-396.

doi:10.1111/j.1365-2249.2008.03641.x

[2] Gruber, C., et al. (2008) History of respiratory infections in the first $12 \mathrm{yr}$ among children from a birth cohort. Pediatric Allergy and Immunology, 19, 505-512. doi:10.1111/j.1365-2249.2008.03641.x

[3] van der Gaag, E.J. and van Droffelaar, N. (2012) Upper respiratory tract infections in children: A normal stage or high parental concern? Open Journal of Pediatrics, in press.

[4] Steinberg, L. (2001) We know some things: Adolescentparent relationships in retrospect and prospect. Journal of Research on Adolescence, 11, 1-20. doi:10.1111/1532-7795.00001

[5] Coplan, R.J., et al. (2002) Authoritative and authoritarian mothers' parental goals, attributions and emotions across different childrearing contexts. Parenting: Science and Practice, 2, 1-26. doi:10.1207/S15327922PAR0201_1

[6] Maccoby, E.E. and Martin, J.A. (1983) Socialization in the context of the family: Parent-child interaction. In: Hetherington, E.M., Ed., Handbook of Child Psychology: (Vol. 4.) Socialization, Personality, and Social Development, 4th Edition, Routledge, New York, 1-101.

[7] Steinberg, L., et al. (1989) Authoritative parenting, psychosocial maturity, and academic success among adolescents. Child Development, 60, 1424-1436. doi:10.2307/1130932 
[8] Radziszewska, B., et al. (1996) Parenting style and adolescent depressive symptoms, smoking, and academic achievement: Ethnic, gender, and SES differences. Journal of Behavioral Medicine, 19, 289-305.

[9] Shah, R. and Waller, G. (2000) Parental style and vulnerability to depression: The role of core beliefs. The Journal of Nervous and Mental Disease, 188, 19-25. doi:10.1097/00005053-200001000-00004

[10] Rothrauff, T.C., et al. (2009) Remembered parenting styles and adjustment in middle and late adulthood. The Journal of Gerontology Series B: Psychological Sciences and Social Science, 64, 137-146. doi:10.1093/geronb/gbn008

[11] Hoerr, S.L., et al. (2009) Associations among parental feeding styles and children's food intake in families with limited incomes. International Journal of Behavioral $\mathrm{Nu}$ trition and Physical Act, 6, 55. doi:10.1186/1479-5868-6-55

[12] Rhee, K.E., et al. (2006) Parenting styles and overweight status in first grade. Pediatrics, 117, 2047-2054. doi:10.1542/peds.2005-2259
[13] Chen, J.L. and Kennedy, C. (2007) Factors associated with obesity in Chinese-American children. Pediatric Nursing, 31, 110-115.

[14] Wake, M., et al. (2007) Preschooler obesity and parenting styles of mothers and fathers: Australian national population study. Pediatrics, 120, e1520-e1527.

[15] McClure, A.C., et al. (2010) Characteristics associated with low self-esteem among US adolescents. American Academy of Pediatrics, 10, 238-244. doi:10.1016/j.acap.2010.03.007

[16] Baumrind, D. (1996) The discipline controversy revisited. Family Relations, 45, 405-414. doi:10.2307/585170

[17] Baumrind, D. (1971) Current patterns of parental authority. 4th Edition, American Psychological Association, Washington DC.

[18] Barber, B.K. and Olsen, J.A. (1997) Socialization in context: Connection, regulation, and autonomy in the family, school, and neighborhood, and with peers. Journal of Adolescent Research, 12, 287-315. doi:10.1177/0743554897122008 


\section{APPENDIX: QUESTIONNAIRE ABOUT HEALTH, CHILD FACTORS, RULES AND DEMANDINGNESS}

1) What is the degree of infection (in days per month), the antibiotics used (number of courses in 3 months) and how many days does your child have a common cold in the last 3 months?

2) Does your child use medication (choose from; no or yes, namely...)?

3) Does your child has a known illness or is treated by a general practitioner or pediatrician (choose from; no or yes, namely...)?

4) How is your health (parents) (choose from; good or not good, namely...)?

5) Does the child go to a day care center or school (choose from; day care center, school, stays at home, or others)?

6) a) What activities does the child do with you (parents) (choose from doing handiworks, doing grocery shopping, watching television, playing a game, doing everything together or others); b) What is the favorite paste time of your child (choose from doing handiworks, playing outside, reading a book, watching television, behind the computer)? Child factors.

7) How does your child play (choose from enthusiastic or boisterous)?

8) Does your child play alone (choose from alone or continuously attracts the parents attention)?

9) How is the behavior of your child during meals (choose whatever fits your child (multiple answers possible); continuously moving around, plays while the rest of the family is eating, slow eater)? Demandingness and complex rules.

10) Who decides how much your child eats (choose from the child, the parent, or together)?

11) Do you think you should stimulate your child to eat when he/she doesn't eat (choose from yes or no) and do you dislike doing that (choose from yes or no)?

12) Does your child know what he or she cannot touch (items that are off limits), choose from yes or no?

13) Do you argue a lot with your child (choose from yes or no)? Demandingness and simple rules.

14) Does your child have to taste everything you (the parents) offer (choose from yes or no)?

15) Who decides if your child can watch television (choose from parent, child or together)?

16) How long is your child allowed to watch television (fill out the minutes every day)?

17) At what time does your child go to bed (fill out the time)?

18) Are there bed rituals (choose from goes to sleep immediately, plays in bed for itself but stays in bed, comes several times a night out of bed, only goes to sleep when you stay with your child or other options)?

19) Does your child use the computer (choose from yes or no)?

20) How much time does your child spend behind the computer (fill out the minutes)? 